\section{Improving appearances since 1978}

Back in 1978, Pastelli's first collection was born from the intuition and innovation of Nada and Gianni Pamich. Since then the unique line of dental clothing has gone on to become a worldwide favourite with image conscious professionals, who expect more from their uniform than the run-of-the-mill design.

There is now a range of collections available in a variety of colours, styles and fits from classic, timeless designs to more innovative and contemporary patterns, all of which are guaranteed to simultaneously complement the activity of your work day and impress your patients.

To ensure that you find your perfect uniform, RPA Dental, the exclusive UK Pastelli distributor, will work closely with you to establish which garments best suit your shape, personality and clinical needs. Together, you can rest assured that your work attire will tick all the boxes.

To see how RPA Dental can transform your dental practice, call 0800 0933975, visit www.rpadental.net or email jo@rpadental.net.
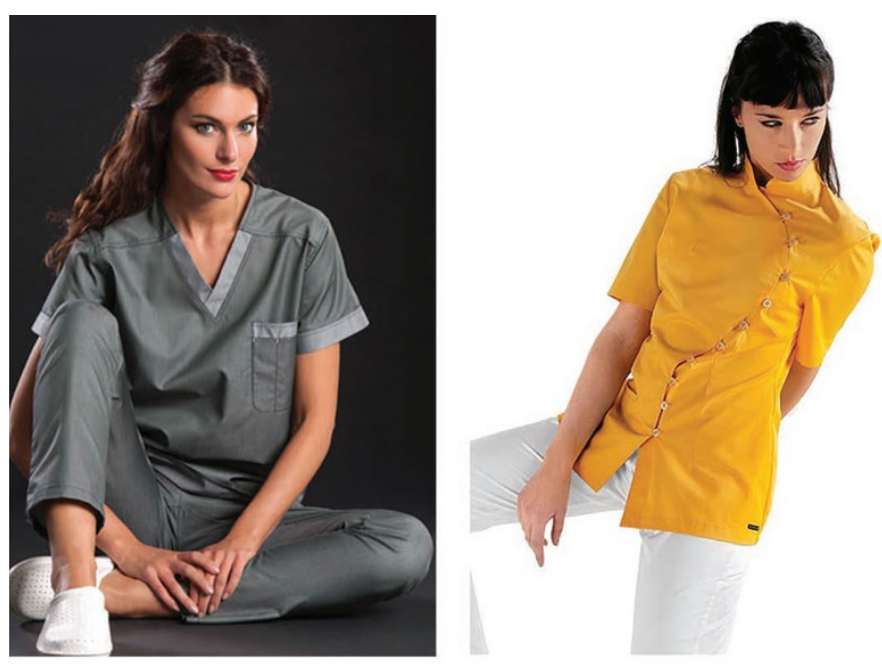

\section{Leave it to the experts}

EndoCare has an expert team of specially trained endodontists to help you with complicated cases.

Endodontic procedures can be difficult - not to mention time consuming - and they can very often leave a patient in more pain than they were originally in if something goes wrong. To ensure nothing does, refer your patients to EndoCare.

The team of endodontic specialists, headed by Dr Michael Sultan, have been expertly trained to carry out even the most complex endodontic cases, using the very latest technologies. This means that your patients will receive nothing but the very best technical care while in the EndoCare chair.

What's more, the EndoCare team are dedicated to providing a caring, patient-focused service, which means your patients will be well looked after by an empathetic and compassionate team of professionals. When you refer a patient to EndoCare you will become part of a special partnership, built on professional trust and due diligence, to ensure that the patient gets the very best outcome possible.

Call 02072240999 or visit www.endocare.co.uk.

\section{Fast, precise, gentle}

Piezosurgery using piezomed instruments has become a widely recognised technique in implantology, thanks to the greater level of precision that these devices afford.

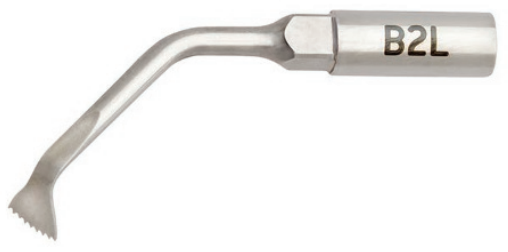

The accuracy of the cutting helps to reduce blood loss and minimise the risk of accidental soft tissue harm, which helps to increase visibility in the working area during surgery. Along with accelerated healing and reduced post-treatment discomfort for the patient, there is also less thermal damage, which minimises the likelihood of bone necrosis.

For best results, the range of Piezomed instruments from leading manufacturer, W\&H offer a continuous supply of coolant through the instrument to near the operating point, to guarantee optimal cooling of both the tip and of the working area.

There are a variety of powerful yet gentle instruments available, including a fine-toothed instrument for horizontal cuts with minimal bone loss in hard-to-reach areas, an instrument for splitting the alveolar ridge, an instrument for modelling and contouring the bone surface, and more.

Efficient, atraumatic and easy to operate, the W\&H Piezomed instrument range is the ideal partner for implant surgery. To find out more visit www.wh.com/en_uk, call 01727874990 or email office.uk@wh.com.

\section{Deciding on dental plans}

Where do dental health plans rank in benefits packages? In 2012, there was a sharp contradiction between employers' recognition of the importance of dental health to employees' well-being, at $8 \%$, and the actual number of employers who offered dental health schemes, which was less than $25 \%$ in one survey.

In 2016, the situation was little changed, with the Munroe Sutton 2016 Dental Benefits Report finding that $64 \%$ percent of employers did not offer any type of dental scheme. This lack of support for dental health was reflected in their employees' attendance at dental appointments, with almost $30 \%$ admitting they had not visited the dentist in the past two years. For most, cost was the issue; $57 \%$ said they would attend the dentist twice a year if they had assistance with payment.

Among the low-cost benefits schemes that fulfil both employer and employee needs is Munroe Sutton's Dental Discounts, which does not have any exclusions for pre-existing conditions. It includes savings of as much as $20 \%$ on the cost of dental care, access to an extensive network of private dentists and coverage for family members, which was another point of concern for some employees.

Paying attention to what employees really want works to the advantage of employers. For more information, call 08082343558 or visit www.munroesutton.co.uk. 